\title{
Comparing adaptation ability towards climate change impacts between the youth and the older fishermen
}

\begin{abstract}
In recent years, a considerable amount of studies published locally which focused on the influence of age on climate change ability. Accordingly, this has driven the present study to achieve its main objective which is to compare the adaptation ability between youth and older fishermen. The current research is quantitative in nature; hence, a survey was conducted on a total of 259 youth and older fishermen residing in different states of Malaysia, namely Pulau Pinang, Terengganu, Johor, and Kedah. The present study managed to conclude a unique and important result which stated that youth and older fishermen within the context of Malaysia have an equally strong adaptation ability. In regard to this matter, a number of recommendations were presented at the end of this paper with the hope that it can act as a basis for future scholars to conduct more climate change related studies.
\end{abstract}

Keyword: Climate change; Fisherman; Adaptation; Community development 